\title{
An Ensemble Covariance Framework for Quantifying Forced Climate Variability and Its Time of Emergence
}

\author{
VINEEL YeTTELLA \\ Department of Atmospheric and Oceanic Sciences, and Cooperative Institute for Research in Environmental \\ Sciences, University of Colorado Boulder, Boulder, Colorado \\ JEFFREY B. WEISS \\ Department of Atmospheric and Oceanic Sciences, University of Colorado Boulder, Boulder, Colorado \\ JENNIFER E. KAY \\ Department of Atmospheric and Oceanic Sciences, and Cooperative Institute for Research in Environmental \\ Sciences, University of Colorado Boulder, Boulder, Colorado
}

Angeline G. PENDERGRASS

National Center for Atmospheric Research, Boulder, Colorado

(Manuscript received 25 October 2017, in final form 10 February 2018)

\begin{abstract}
Climate variability and its response to increasing greenhouse gases are important considerations for impacts and adaptation. Modeling studies commonly assess projected changes in variability in terms of changes in the variance of climate variables. Despite the distant and impactful covariations that climate variables can exhibit, the covariance response has received much less attention. Here, a novel ensemble framework is developed that facilitates a unified assessment of the response of the regional variances and covariances of a climate variable to imposed external forcings and their time of emergence from an unforced climate state.

Illustrating the framework, the response of variability and covariability of land and ocean temperatures is assessed in the Community Earth System Model Large Ensemble under historical and RCP8.5 forcing. The results reveal that land temperature variance emerges from its preindustrial state in the 1950s and, by the end of the twenty-first century, grows to 1.5 times its preindustrial level. Demonstrating the importance of covariances for variability projections, the covariance between land and ocean temperature is considerably enhanced by 2100 , reaching 1.4 times its preindustrial estimate. The framework is also applied to assess changes in monthly temperature variability associated with the Arctic region and the Northern Hemisphere midlatitudes. Consistent with previous studies and coinciding with sea ice loss, Arctic temperature variance decreases in most months, emerging from its preindustrial state in the late twentieth century. Overall, these results demonstrate the utility of the framework in enabling a comprehensive assessment of variability and its response to external climate forcings.
\end{abstract}

\section{Introduction}

The Earth's climate is changing rapidly in response to anthropogenic radiative forcing (IPCC 2013). The response manifests as changes in not only the mean state of the climate but also in the variability about the mean state. While the potential consequences of mean state

\footnotetext{
Corresponding author: Vineel Yettella, vineel.yettella@colorado. edu
}

changes have long been recognized (IPCC 1990), variability changes are also important (e.g., Katz and Brown 1992; Addo-Bediako et al. 2000; Wheeler et al. 2000; Schär et al. 2004; Porter and Semenov 2005). Changes in interannual (and longer time-scale) variability are of particular interest because of the protracted nature of the associated climate anomalies (Rajagopalan and Lall 1998; Meehl and Tebaldi 2004). The occurrence of an extreme anomaly that is of an extended duration (a month, a season, or longer) can translate into catastrophic 
outcomes. For example, the 2003 extreme European summer, which was attributed to an increased temperature variability regime in combination with mean climate warming (Schär et al. 2004), claimed more than 52000 lives (Larsen 2006). The low rainfall and unprecedented heat further resulted in crop failures, reduced plant respiration and growth, and consequently a large positive flux of $\mathrm{CO}_{2}$ into the atmosphere (Ciais et al. 2005).

Recognizing such severe societal and ecological effects of extended climate anomalies, a natural question to ask is: how will interannual variability change in a warmer climate? Using climate models, previous work has addressed this question for various climate variables at global (e.g., Räisänen 2001; Stouffer and Wetherald 2007; Boer 2009; Wetherald 2009) and regional (e.g., Schär et al. 2004; Scherrer et al. 2008; Fischer et al. 2012) scales under different anthropogenic forcing scenarios. While these studies have uncovered robust variability changes that can be expected with a high degree of confidence in a warmer climate (e.g., Huntingford et al. 2013; Holmes et al. 2016) and have improved our understanding of the climate system, they leave two key areas unexplored that are of specific interest to this paper.

First, existing model studies on interannual variability have largely focused on the influence of external climate forcing on the variance. On interannual (and longer) time scales, climate variables can exhibit covariations across distant locations through numerous well-known circulation patterns (e.g., Bjerknes 1969; Wallace and Gutzler 1981; Simmons et al. 1983; Trenberth and Shea 1987; Thompson and Wallace 1998) as well as potentially undiscovered patterns in the coupled climate system. These covariations often are associated with enormous impacts on a global scale (IPCC 2013). Therefore, interannual variability is in general a problem of not only the variances but also the covariances associated with interacting regions. While the joint variability associated with a system of interacting regions has alternatively been investigated in terms of empirical orthogonal functions or variants thereof (Jolliffe 2002), these techniques are not designed for the goal of physical interpretation (Hannachi et al. 2007). The variances and covariances on the other hand are directly physically interpretable. Despite its obvious physical relevance and importance, only a few studies have considered the covariance response (e.g., Leeds et al. 2015; LaJoie and DelSole 2016; Poppick et al. 2016) to anthropogenic forcing.

Recognizing the importance of covariance to interannual variability naturally leads us to the second area of our study: the time of emergence of forced covariance signals from an unforced climate. Changes in variability that are of considerable magnitude relative to the variability that might naturally occur in an unforced climate can translate into major impacts (e.g., Kunkel et al. 1999; Fischer et al. 2007; Robine et al. 2008). As such, assessing the time of emergence of forced variability is important for adaptation and mitigation planning. It is also an important step in the attribution of variability changes to a specific cause, for example, anthropogenic forcing (Bindoff et al. 2013). While the emergence of forced mean state and variance signals has received a lot of attention (e.g., Giorgi and Bi 2009; Deser et al. 2012; Hawkins and Sutton 2012; Mora et al. 2013; although also see Hawkins et al. (2014); Thompson et al. 2015; Yettella and Kay 2017; LaJoie and DelSole 2016), fewer studies have looked at the time of emergence of covariance signals (e.g., Poppick et al. 2016).

Estimating forced variability statistics using a single model simulation is challenging. Variability statistics under rapidly changing forcing can evolve in time periods shorter than those that are required for their accurate estimation with a single model realization. That is, the conventional idea of computing variability statistics from a long model simulation (Leith 1978) is of limited use in a transient climate change setting, and one necessarily has to resort to using ensembles of model simulations. Initial condition climate model ensembles are particularly useful here (Collins and Allen 2002; Kay et al. 2015). The members of such an ensemble are simulated under the same external forcing with small perturbations introduced at the start of their integrations. After the memory of the initial conditions is lost, each member evolves independently (Lorenz 1963; Deser et al. 2012). As such, the members of such an ensemble serve as independent samples for the computation of forced statistics.

In this paper, we develop a framework for analyzing an initial condition ensemble under transient forcing that facilitates a unified assessment of the regional variances and covariances and their contributions to global variance. We accomplish three specific goals with the framework. First, we decompose global variance into subjectively chosen regional variance and covariance components. Such a decomposition is useful in understanding the contributions of the regional variances and covariances to global variance. Second, we offer a simple method for calculating the evolving regional variances and covariances along with their sampling uncertainties in climates undergoing transient forcing using initial condition climate model ensembles. Third, we address the time of emergence of forced variability statistics. Specifically, we derive the estimates of the regional variances and covariances along with their 
sampling uncertainties in long unforced control simulations. By comparing the forced variability statistics with their unforced estimates in the presence of sampling uncertainties, the time of emergence can be quantified.

After developing the framework, we demonstrate its application in a state-of-the-art initial condition ensemble: the Community Earth System Model Large Ensemble (CESM-LE; Kay et al. 2015). The CESM-LE consists of multiple realizations of a single model [CESM(CAM5); Hurrell et al. 2013] under historical and representative concentration pathway 8.5 (RCP8.5; Meinshausen et al. 2011) forcing scenarios, while a companion multicentury preindustrial control run provides a stationary climate for the derivation of baseline statistics. Leveraging the CESM-LE and the preindustrial run, we explore the forced evolution and emergence of the surface temperature variability statistics associated with two distinct regional decompositions. The first decomposition consists of two regions: the land and the ocean. The second decomposition consists of three regions: the Arctic $\left(70^{\circ}-90^{\circ} \mathrm{N}\right)$, the Northern Hemisphere midlatitudes $\left(30^{\circ}-\right.$ $70^{\circ} \mathrm{N}$; midlatitudes herein), and the rest of the globe (all regions on the globe except the Arctic and northern midlatitudes).

We organize the paper as follows: In section 2, we detail our methods and describe the model. In section 3, we utilize the framework to explore the variability statistics in the two decompositions of simulated global interannual variance. As we will show, our results highlight the importance of regional covariances to global interannual variance. Finally, in section 4 , we offer a summary and concluding remarks.

\section{Methods and data}

\section{a. Decomposition of global variance into regional variance and covariance components}

A key goal of the framework is identifying the contributions of regional variances and covariances to global variance. We achieve this by a simple diagnostic relationship between global variance and regional variances and covariances, which we develop in this section. While the decomposition is applicable to any climate variable of interest and any time scale, we apply the framework to interannual surface temperature variability.

Let $S=\left\{r_{1}, r_{2}, r_{3}, \ldots, r_{n}\right\}$ be a system of $n$ nonoverlapping regions, with the $i^{\text {th }}$ region denoted by $r_{i}$, which together cover the entire surface of the globe. Let $T_{r}$ represent the surface temperature averaged over a region $r$ and over a period of interest, for example, season, month, or year. The globally averaged temperature $T_{g}$ can be expressed as an area-weighted sum of temperatures averaged over the $n$ regions:

$$
T_{g}=\sum_{i=1}^{n} f_{i} T_{r_{i}},
$$

where $f_{i}=A_{r_{i}} / A_{g}, A_{r_{i}}$ denotes the area of region $r_{i}$, and $A_{g}$ is the area of the globe. The variance of $T_{g}$ can be expressed in terms of the covariance matrix $\mathbf{C}$ :

$$
\begin{gathered}
\sigma_{T_{g}}^{2}=\mathbf{f}^{\mathrm{T}} \mathbf{C f} \\
\mathbf{C}=\left[\begin{array}{cccc}
\sigma_{T_{r_{1}}}^{2} & \operatorname{cov}\left(T_{r_{2}}, T_{r_{1}}\right) & \ldots & \operatorname{cov}\left(T_{r_{n}}, T_{r_{1}}\right) \\
\operatorname{cov}\left(T_{r_{1}}, T_{r_{2}}\right) & \sigma_{T_{r_{2}}}^{2} & \ldots & \operatorname{cov}\left(T_{r_{n}}, T_{r_{2}}\right) \\
\vdots & \vdots & \ddots & \vdots \\
\operatorname{cov}\left(T_{r_{1}}, T_{r_{n}}\right) & \operatorname{cov}\left(T_{r_{2}}, T_{r_{n}}\right) & \ldots & \sigma_{T_{r_{n}}}^{2}
\end{array}\right], \quad \text { and } \\
\mathbf{f}=\left[\begin{array}{c}
f_{1} \\
\vdots \\
f_{n}
\end{array}\right]
\end{gathered}
$$

where $\mathrm{T}$ denotes transpose and cov denotes covariance. Grouping terms arising from the variances and covariances separately, Eq. (2) can be written as the following "decomposition":

$$
\sigma_{T_{g}}^{2}=\sum_{i=1}^{n} f_{i}^{2} \sigma_{T_{r_{i}}}^{2}+\sum_{i=2}^{n} \sum_{j=1}^{i-1} 2 f_{i} f_{j} \operatorname{cov}\left(T_{r_{i}}, T_{r_{j}}\right) .
$$

We note from Eq. (5) that the decomposition of $\sigma_{T_{g}}^{2}$ yields a total of $n(n+1) / 2$ independent area-weighted components: $n$ variance components of the form $f_{i}^{2} \sigma_{T_{r_{i}}}^{2}$, and $n(n-1) / 2$ covariance components of the form $2 f_{i} f_{j} \operatorname{cov}\left(T_{r_{i}}, T_{r_{j}}\right)$. By expressing the regional variance and covariance components as fractions of $\sigma_{T_{g}}^{2}$, the contribution of regional variances and covariances to global variance can be assessed in a straightforward manner.

\section{b. Forced evolution and time of emergence of variability statistics}

\section{1) ESTIMATION OF FORCED VARIABILITY COMPONENTS IN INITIAL CONDITION ENSEMBLES}

To estimate the forced components in an $M$-member initial condition ensemble undergoing transient forcing, we begin with the ensemble estimates of the variances and covariances at each year $t$. Let $T_{r}^{t}$ represent the temperature averaged over region $r$ and over a period of interest during year $t$. Some examples of potential periods of interest are monthly means, seasonal means, 
and annual means. Unbiased ensemble estimates of the mean $\bar{T}_{r}^{t}$ and ensemble variance $\hat{\sigma}_{T_{r}^{t}}$ of $T_{r}^{t}$ are

$$
\begin{aligned}
\bar{T}_{r}^{t} & =\frac{1}{M} \sum_{\alpha=1}^{M} T_{r}^{t, \alpha} \text { and } \\
\hat{\sigma}_{T_{r}^{t}}^{2} & =\frac{1}{M-1} \sum_{\alpha=1}^{M}\left(T_{r}^{t, \alpha}-\bar{T}_{r}^{t}\right)^{2},
\end{aligned}
$$

where $T_{r}^{t, \alpha}$ denotes the $\alpha$ th ensemble realization, and $T_{r}^{t, \alpha}-\bar{T}_{r}^{t}$ is the residual obtained by subtracting the ensemble mean from the $\alpha$ th ensemble realization. Note that the residuals represent a slightly damped realization of internal variability (LaJoie and DelSole 2016). Both the overbar (e.g., $\bar{T}_{r}$ ) and the hat symbols (e.g., $\hat{\sigma}_{T_{r}}^{2}$ ) denote unbiased estimates. The unbiased ensemble covariance associated with regions $r$ and $s$ is

$$
\widehat{\operatorname{cov}}\left(T_{r}^{t}, T_{s}^{t}\right)=\frac{1}{M-1} \sum_{i=1}^{M}\left(T_{r}^{t, \alpha}-\bar{T}_{r}^{t}\right)\left(T_{s}^{t, \alpha}-\bar{T}_{s}^{t}\right) .
$$

Theoretically, in the limit of an infinite number of ensemble members, the unbiased estimates presented above converge to the population variances and covariances. In practice, however, the number of ensemble members that can be generated is limited by computational expense and therefore is finite. Our results from the CESM-LE suggest that, even with large climate model ensembles consisting of as many as 40 ensemble members, the ensemble estimates of the second moments [Eqs. (7) and (8)] and as a consequence, of the components, are in general very noisy. That is, the estimates in practice are associated with large sampling uncertainty.

The sampling uncertainty in the noisy ensemble estimates can be reduced and more precise estimates of the components can be obtained by fitting a statistical model in time. In the case of a linear time dependence, a simple linear fit across the time period under investigation can serve as a reasonable statistical model. However, as will be clear from the results, the time dependence of climate variability under transient climate forcing can be very nonlinear. Therefore, to obtain more precise estimates in the general setting of nonlinear time dependence, we use a smoothing approach. For each year, we apply a 31-yr window centered on that year. Our choice of the window length is motivated by the World Meteorological Organization (WMO) approach of calculating climatic normals over a 30 -yr period. In the case of a linear time dependence of climate variability, the smoothing approach yields results that are very close to the estimates from ordinary linear regression.

Sensitivity tests (not shown) revealed that the results were virtually identical for window lengths ranging from 25 to $45 \mathrm{yrs}$. We estimate the value of the forced components at year $t$ by averaging across the window. This results in smoothed estimates of the forced components:

$$
\begin{gathered}
<f_{i}^{2} \hat{\sigma}_{T_{r_{i}}^{t}}^{2}>=\frac{1}{31} \sum_{k=t-15}^{k=t+15} f_{r_{i}}^{2} \hat{\sigma}_{T_{r_{i}}^{k}}^{2} \text { and } \\
<2 f_{i} f_{j} \widehat{\operatorname{cov}}\left(T_{r_{i}}^{t}, T_{r_{j}}^{t}\right)>=\frac{1}{31} \sum_{k=t-15}^{k=t+15} 2 f_{i} f_{j} \widehat{\operatorname{cov}}\left(T_{r_{i}}^{k}, T_{r_{j}}^{k}\right),
\end{gathered}
$$

and a smoothed version of the decomposition:

$$
\begin{aligned}
<\hat{\sigma}_{T_{g}^{t}}^{2}>= & \sum_{i=1}^{n} f_{i}^{2}<\hat{\sigma}_{T_{r_{i}}^{t}}^{2}> \\
& +\sum_{i=2}^{n} \sum_{j=1}^{i-1} 2 f_{i} f_{j}<\widehat{\operatorname{cov}}\left(T_{r_{i}}^{t}, T_{s_{i}}^{t}\right)>,
\end{aligned}
$$

where the angle brackets $<>$ denote smoothing over time. The forced evolution of the variances and covariances is assessed in terms of the smoothed estimates of the components presented above. Likewise, the contribution of the variances and covariances to global variability is assessed as ratios of the smoothed components relative to global variability $<\hat{\sigma}_{T_{g}^{t}}^{2}>$.

\section{2) ESTIMATION OF VARIABILITY COMPONENTS IN UNFORCED SIMULATIONS}

Assessing time of emergence entails detecting significant differences between forced and unforced variability. Having developed a simple method for estimating forced variability statistics in transient climate simulations, we here present the estimation of variability statistics in unforced control simulations.

Following Schneider and Griffies (1999), the unforced components can be estimated from a single $N$ year control simulation:

$$
\begin{aligned}
f_{i}^{2} \hat{\sigma}_{T_{r_{i}}}^{2} & =\frac{1}{N-1} \sum_{l=1}^{N}\left(T_{r_{i}}^{l}-\bar{T}_{r_{i}}^{\mathrm{clim}}\right)^{2}, \\
2 f_{i} f_{j} \widehat{\operatorname{cov}}^{\operatorname{clim}}\left(T_{r_{i}}, T_{r_{j}}\right) & =\frac{2 f_{i} f_{j}}{N-1} \sum_{l=1}^{N}\left(T_{r_{i}}^{l}-\bar{T}_{i}^{\mathrm{clim}}\right)\left(T_{r_{j}}^{l}-\bar{T}_{j}^{\mathrm{clim}}\right),
\end{aligned}
$$

and

$$
\bar{T}_{r}^{\operatorname{clim}}=\frac{1}{N} \sum_{l=1}^{N} T_{r}^{l},
$$

where the superscript clim refers to climatological statistics of an unforced climate.

\section{3) TIME OF EMERGENCE OF FORCED VARIABILITY COMPONENTS}

Because of the finite number of ensemble members and the finite length of control simulations, estimates of 
the forced variability necessarily contain sampling uncertainties. Quantifying time of emergence is a problem of the detection of significant differences between the forced and unforced variability statistics in the presence of sampling uncertainty.

Two difficulties arise when attempting to estimate the sampling uncertainties in unforced variability statistics. First, the underlying probability distributions of climatic variables are not always known, which precludes analytical estimation of the uncertainties. Second, climatic time series, in general, exhibit autocorrelation. Autocorrelation complicates the estimation of sampling uncertainties in the second moments even when the underlying distributions are known.

A statistical resampling technique that facilitates the estimation of sampling uncertainties in the presence of serial dependence, without requiring the knowledge of the underlying distributions, is the moving-block bootstrap (Wilks 2011). In this technique, multiple realizations of the control time series are generated by randomly selecting those series with replacement and splicing contiguous blocks of data in time such that the resulting realizations are of the same length as the original time series. Sample bootstrap estimates of the unforced variability statistics are calculated for each realization, and the sampling uncertainty is quantified as the spread across the distribution of the bootstrap estimates.

Application of the moving-block bootstrap relies on a few critical assumptions: 1) the climate statistics are stationary in time, 2) the temporal dependence of climatic variables is preserved within blocks, 3) there is relatively weak dependence between blocks, and 4) the spread across the bootstrap estimates sufficiently captures the variability associated with the stochastic process that generated the data. The assumption of stationarity is generally well satisfied in control simulations that have equilibrated under constant forcing. The other assumptions are satisfied by choosing an appropriate block length. As noted by Wilks (2011) and originally conceived by Politis et al. (1999), a straightforward, data-driven choice of the block length is a value from a range of lengths to which the spread across the bootstrap estimates is insensitive (the so-called minimum volatility method). We note that there is no universal optimal block length and the optimal block length based on the minimum volatility method will, in general, vary for different time series. See Efron (1981) for a formal treatment of the bootstrap technique.

For the present analysis, we derive the sampling distributions of the unforced variability statistics from 10000 random time series realizations generated by the moving-block bootstrap. Sensitivity tests (not shown) for the spread across the sampling uncertainties in the unforced estimates with blocks lengths varying from 6 to 12 yrs yielded essentially the same results. Following the minimum volatility method, we thus arbitrarily choose a block length of $10 \mathrm{yrs}$ for bootstrapping.

Estimating the sampling uncertainties associated with the forced variability statistics in initial condition ensembles is relatively straightforward via bootstrapping. We outline the steps below:

1) Create multiple (for the present analysis, 10000) bootstrapped ensembles consisting of $M$ members, each by uniformly sampling with replacement the entire time series of the members in the original $M$-member ensemble. Sampling the entire time series of the ensemble members completely preserves the temporal structure in the time series.

2) For each bootstrapped ensemble, compute smoothed estimates of the forced components [Eqs. (9) and (10)]. This results in a distribution of bootstrap estimates at each time point. The spread across the distribution is then used to compute sampling uncertainty.

Time of emergence is assessed in terms of the spread across the distributions of the forced and unforced bootstrap estimates. For the investigations in this paper, we use $95 \%$ confidence intervals as the metric for the spread. When there is no overlap between the bootstrapped $95 \%$ confidence intervals of the forced and unforced estimates, the forced estimates are considered to be significantly different from an unforced climate at that time point and are considered to have emerged.

\section{c. Data ellipses}

Central to the variability assessment framework is the covariance matrix of regional variances and covariances. The data ellipse (Friendly et al. 2013) serves as a useful tool to visualize the covariance matrix and forced changes in the covariance matrix.

We present its construction and interpretation for a system of two regions. For systems with a larger number of regions, pairwise ellipses can be utilized. For a system $S=\left\{r_{x}, r_{y}\right\}$ and its covariance matrix $\mathbf{C}$ as defined in section $2 \mathrm{~b}(1)$, the standard data ellipse centered at zero is constructed from (Friendly et al. 2013):

$$
\mathbf{z}^{\mathrm{T}} \mathbf{C}^{-1} \mathbf{z}=k^{2},
$$

where $\mathbf{z}=\left[\begin{array}{l}T_{x}^{\prime} \\ T_{y}^{\prime}\end{array}\right]$ is a point in the coordinate system defined by $T_{x}^{\prime}$ on the $x$ axis and $T_{y}^{\prime}$ on the $y$ axis, $k$ is a constant, and $T_{x}^{\prime}=T_{x}-\bar{T}_{x}$ denotes ensemble-mean removed temperature anomaly. The geometrical properties of the ellipse serve as a sufficient visual summary of the second moments: 


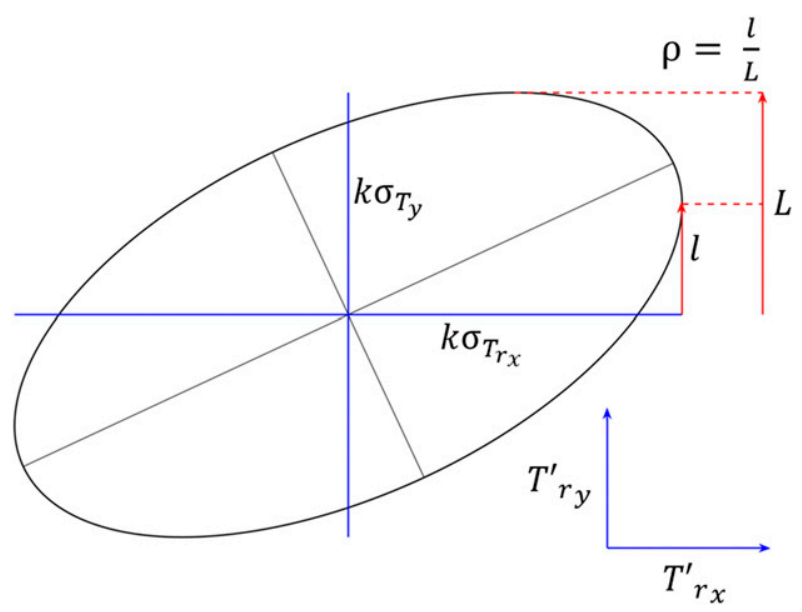

FIG. 1. Schematic of an std data ellipse constructed from Eq. (13) for variables $T_{r x}$ and $T_{r y}$. The projections of the ellipse on the coordinate axes (blue solid lines) give the std devs of the variables. The ratio of the vertical tangent length $(l)$ to the height of the horizontal tangent line above the horizontal axis $(L)$ gives the correlation $\rho$. The variable $k$ is a const that defines the ellipse surface [see Eq. (13)]. If $T_{r x}$ and $T_{r y}$ are jointly Gaussian, the data ellipse represents contours of const probability and the area bounded by the ellipse represents the probability of the joint occurrence of the variables.

1) The projections of the ellipse onto the coordinate axes are directly related to the standard deviations of the respective variables (Fig. 1). That is to say, the relative magnitudes of the variances of $T_{r x}$ and $T_{r y}, \sigma_{T_{r_{x}}}^{2}$ and $\sigma_{T_{r_{y}}}^{2}$ can be quickly approximated from the ellipse.

2) The correlation between $T_{r x}$ and $T_{r y}, \rho$ can be visually approximated as the ratio of the length of the vertical tangent line to the height of the horizontal tangent line above the $x$ axis (Fig. 1). As such, changes in correlations can be visually approximated by the changes in this ratio.

3) The variances and covariances can be retrieved from the ellipse geometry in a straightforward manner:

$$
\begin{gathered}
\theta=\frac{1}{2} \operatorname{atan}\left[\frac{2 \operatorname{cov}\left(T_{r x}, T_{r y}\right)}{\sigma_{T_{r_{x}}}^{2}-\sigma_{T_{r_{y}}}^{2}}\right], \\
l_{\text {major }}^{2}=2 k^{2}\left\{\sigma_{T_{r_{x}}}^{2}+\sigma_{T_{r_{y}}}^{2}\right. \\
\left.+\sqrt{\left(\sigma_{T_{r_{x}}}^{2}-\sigma_{T_{r_{y}}}^{2}\right)^{2}+4\left[\operatorname{cov}\left(T_{r_{x}}, T_{r_{y}}\right)\right]^{2}}\right\}, \\
l_{\text {minor }}^{2}=2 k^{2}\left\{\sigma_{T_{r_{x}}}^{2}+\sigma_{T_{r_{y}}}^{2}\right. \\
\left.-\sqrt{\left(\sigma_{T_{r_{x}}}^{2}-\sigma_{T_{r_{y}}}^{2}\right)^{2}+4\left[\operatorname{cov}\left(T_{r_{x}}, T_{r_{y}}\right)\right]^{2}}\right\},
\end{gathered}
$$

where $\theta$ is the angle made by the major axis with the $x$ axis and $l_{\text {major }}$ and $l_{\text {minor }}$ are the lengths of the major and minor axes.

The geometrical relationships presented above hold regardless of the joint probability distribution of $T_{r x}$ and $T_{r y}$. But if the distribution is Gaussian, the data ellipse has an important probabilistic interpretation. In this case, $\mathbf{z}^{\mathrm{T}} \mathbf{C}^{-1} \mathbf{z}$ is chi-square distributed with two degrees of freedom (Wilks 2011). Thus, on setting $k^{2}=\chi_{2}^{2}(\alpha)$, the ellipse constructed from Eq. (8) represents an approximate $1-\alpha$ probability surface. That is, the ellipse bounds $100(1-\alpha) \%$ of the joint realizations of $T_{r x}$ and $T_{r y}$. As such, changes in the shape of the ellipse under forcing for a given $\alpha$ allows one to readily gauge changes in the joint probabilities.

The variability of space- and/or time-averaged climate variables often follows a Gaussian distribution (Toth 1991). Indeed, on application of a multivariate test for normality (Henze and Zirkler 1990), all pairs of the model $T_{r_{i}}{ }^{\prime}$ s associated with the systems in our study were indistinguishable from a Gaussian at a significance level of 0.01 at all times under consideration. For these reasons, the ellipses in our study are constructed by setting $k^{2}=\chi_{2}^{2}(0.05)$, and may be interpreted as contours of $95 \%$ probability.

For convenience, we drop the hat, overbar, and angle bracket notations in the rest of the paper and the variability statistics where they appear hereafter are to be understood as estimates of the population statistics.

\section{d. Applications to climate model simulations: The CESM large ensemble}

We make use of the CESM-LE: an initial condition ensemble consisting of 40 CESM1(CAM5) simulations at $1^{\circ} \times 1^{\circ}$ resolution. A detailed description of the CESM-LE experimental design can be found in Kay et al. (2015). The CESM-LE includes a 2200-yr preindustrial control run under constant 1850 forcing. The ocean component of this control run was initialized with modern-day ocean observations while the atmosphere, land, and sea ice components were initialized with results from previous CESM1(CAM5) simulations. The initial states of the atmosphere, land, and sea ice components lose their influence on the climate system within a few years of integration while the upper ocean adjusted to a preindustrial state after several decades. With the exception of a small climate drift present in the deep ocean, the control run was in quasi-equilibrium with preindustrial forcing by year 400 . The first ensemble member was initialized using 1 January conditions of a randomly selected year (year 402) of the preindustrial control run and then integrated forward from 

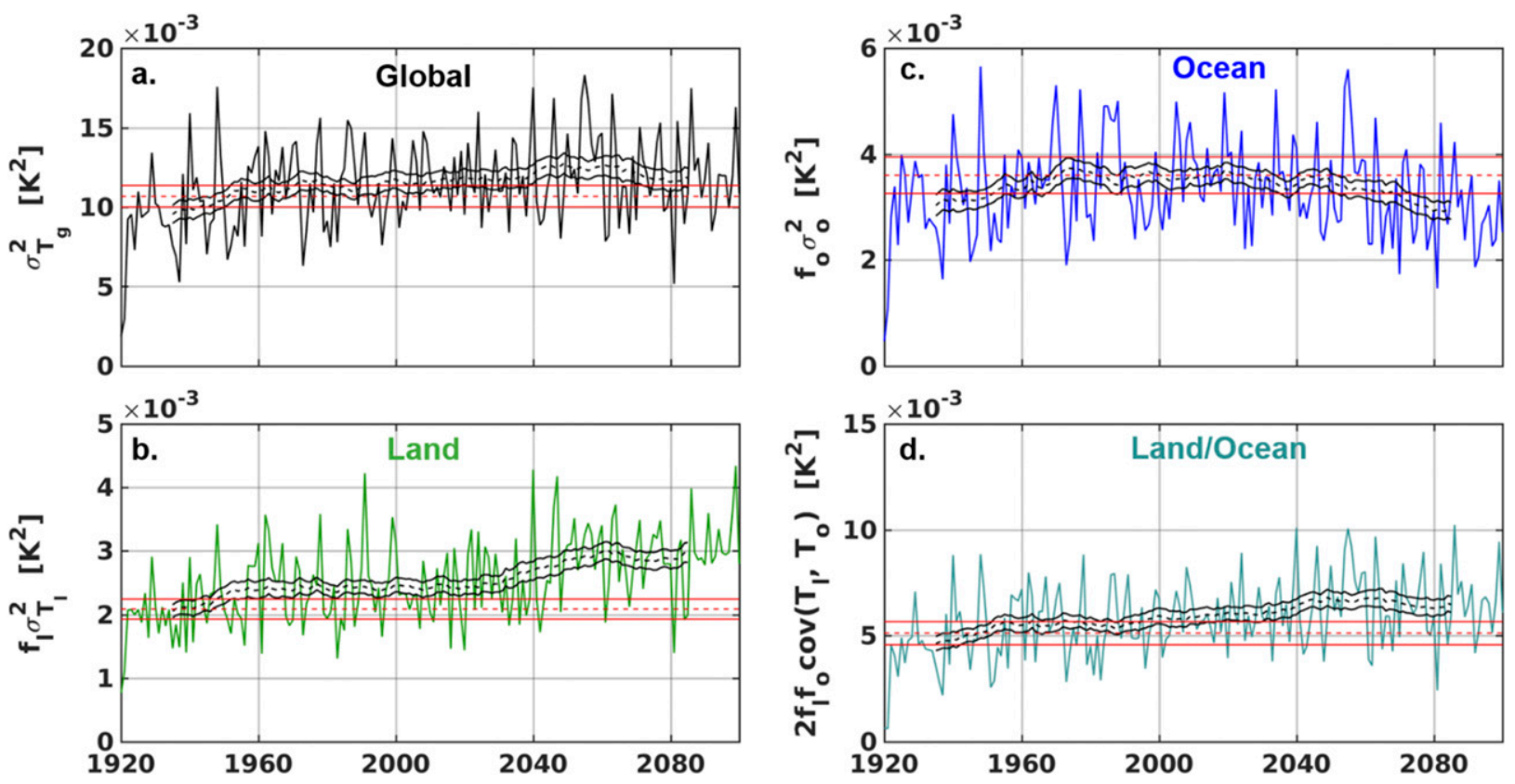

FIG. 2. Decomposition of (a) global $\left(\sigma_{T_{g}}^{2}\right)$ annual temp variance into (b) land $\left(f_{l} \sigma_{T_{l}}^{2}\right)$ and (c) ocean $\left(f_{o} \sigma_{T_{o}}^{2}\right)$ variance components, and (d) the land/ocean $\left[2 f_{l} f_{o} \operatorname{cov}\left(T_{l}, T_{o}\right)\right]$ covariance component in the CESM-LE. Preindustrial estimates are shown by the horizontal red dashed lines in each panel. The noisy time series are the ensemble estimates of the variance and covariance components [see Eqs. (7) and (8)]. Forced estimates derived from smoothing the noisy ensemble time series are shown by the black dashed lines. Ninety-five percent bootstrap confidence intervals for the preindustrial and forced estimates are shown by horizontal red and black solid lines, respectively. The terms $f_{l}$ and $f_{o}$ represent the fractions of global area occupied by land and ocean. Note the different scales on the $y$ axes.

1850 to 2100 under historical (lamarque et al. 2010) and RCP8.5 (Meinshausen et al. 2011) forcing. The rest of the ensemble members were integrated from states that only differed by small perturbations to the air temperature field of the first ensemble member on 1 January, 1920 and integrated forward to 2100 . Chaos leads to a growth in these perturbations, eventually creating spread among the ensemble members.

Using the spread across the independent CESM-LE members, we assess the effect of forcing on the interannual variability statistics of annual surface temperature associated with the land/ocean system and monthly surface temperatures associated with the Arctic/ midlatitude/rest-of-the-globe system. We further assess time of emergence by comparing transiently forced statistics against those estimated from the unforced stationary climate provided by 1800 years (years 400-2200) of the preindustrial control simulation.

\section{Results}

\section{a. Forced interannual temperature variability in a land/ocean decomposition}

Because it offers a simple and interesting application of our framework, we begin by presenting results for the coupled land/ocean system (Figs. 2-4). We start with Fig. 2, which shows the decomposition of the variance in global annual temperature (Fig. 2a) into land (Fig. 2b) and ocean (Fig. 2c) variance components, and a land/ ocean covariance component (Fig. 2d) under historical and future business-as-usual (RCP8.5) forcing in the CESM-LE. Figure $2 b$ shows that greenhouse gas forcing strongly enhances land variance. Under historical forcing, the land variance emerges from its preindustrial state rapidly in just three decades after the start of the ensemble integration in 1920, and under RCP8.5 forcing, rapidly increases to 1.5 times its preindustrial estimate by the end of the twenty-first century. Greenhouse gas forcing, however, has little effect on ocean variance. The ocean variance remains constant at its preindustrial value for most of the integration period, with a small decrease toward the end of the twenty-first century. A critically increasing land variability with constant ocean variability suggests that, under increased greenhouse gases, ocean temperatures exert a stronger influence on land temperature variability. Accordingly, we find that the land/ocean temperature covariance is enhanced substantially. By the end of the integration, the covariance grows to 1.4 times its preindustrial estimate, emerging from its preindustrial state in the first quarter of the twenty-first century. Driven by the increases in the land 


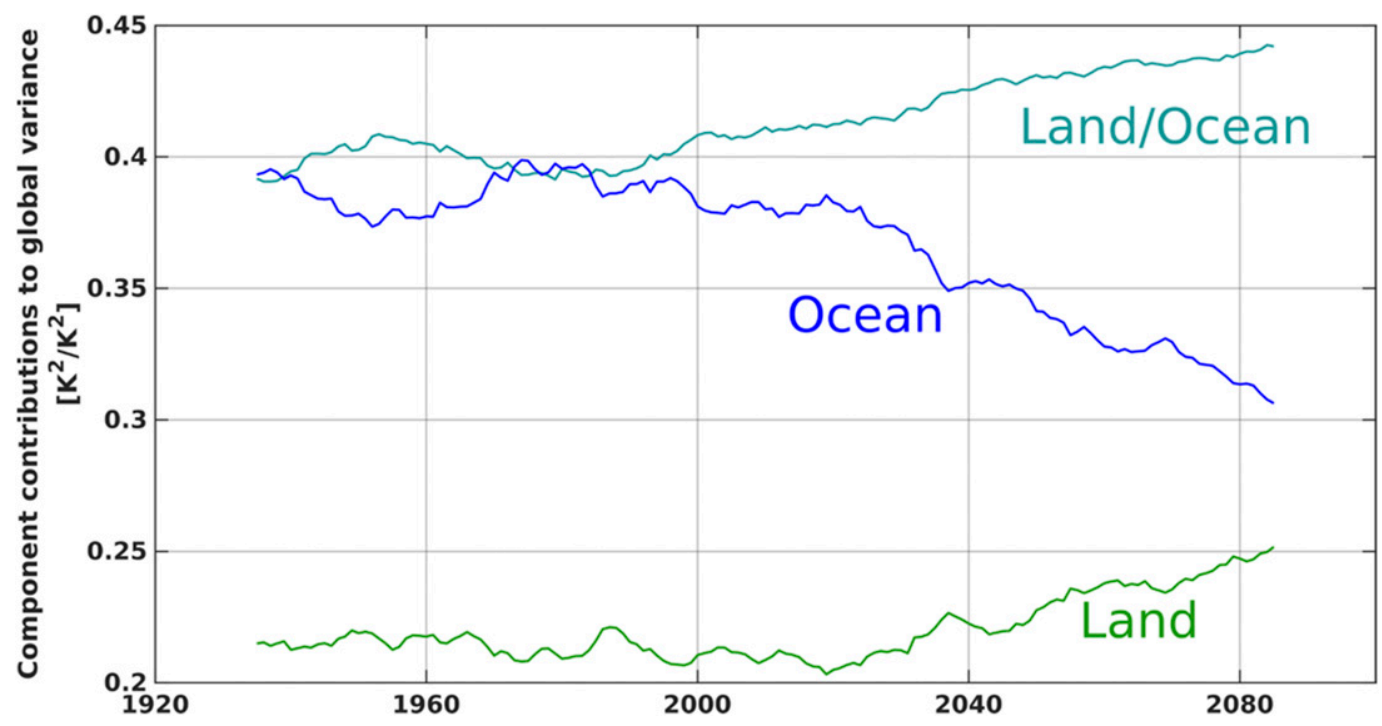

FIG. 3. Contributions of land (green) and ocean (blue) variance components, and land/ocean (cyan) covariance component to global annual temp variance. The contributions are computed as ratios of the components in relation to global annual temp variance and can range from 0 to 1 .

variance and land/ocean covariance, global annual variance grows steadily, emerging in approximately 2040.

We next assess the contributions of the regional variances and covariance to global annual variance. We calculate the contributions as ratios of the variance and covariance components to global annual variance in the CESM-LE and present the ratios in Fig. 3. We find that the land/ocean covariance has the greatest contribution ( $\sim 40 \%$ of global annual variance), that is, almost twice that of the land variance, throughout the integration, demonstrating the importance of the covariance between land and ocean annual temperature to global annual temperature variance. The contribution of the ocean variance is similar to that of the land-ocean covariance in the twentieth century. The land variance has the smallest contribution to the global variance $(\sim 20 \%$ of global annual variance) throughout the integration, despite the larger variance of temperature over land (see data ellipse in Fig. 4), reflecting the smaller fractional area of land ( $29 \%$ of global area). Coinciding with the

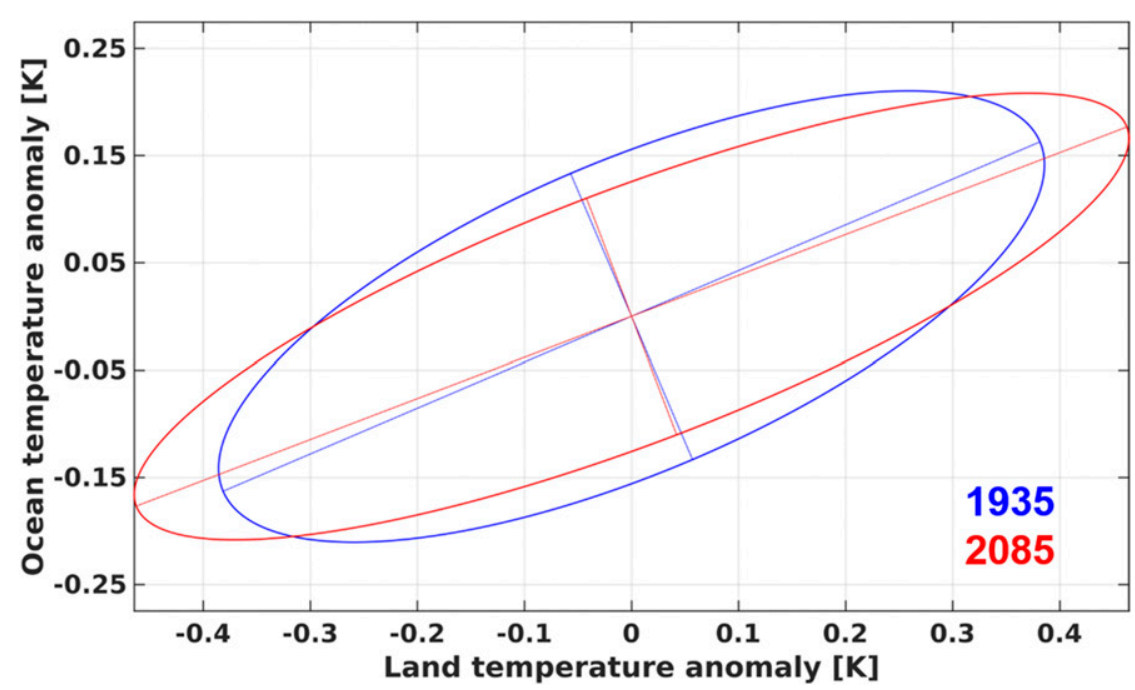

FIG. 4. Ninety-five percent data ellipses for land and ocean temp anomalies at 1935 (blue) and 2085 (red). The ellipses were constructed from forced estimates of the variances and covariances associated with the land/ocean system in the CESM-LE using methods in section $2 b(1)$. Anomalies are calc as devs from the ensemble mean. 

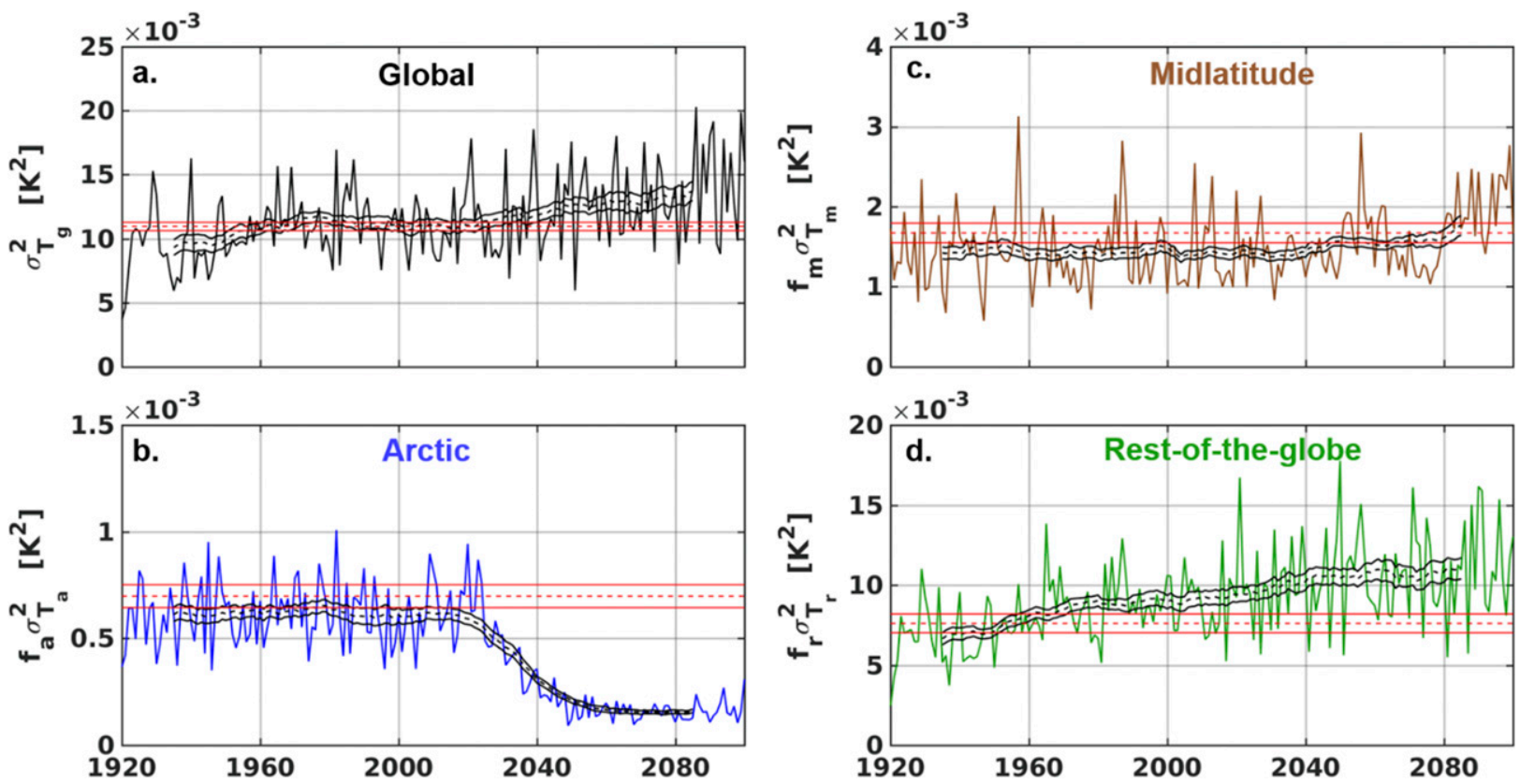

FIG. 5. Decomposition of (a) global $\left(\sigma_{T_{g}}^{2}\right)$ September temp variance into (b) Arctic $\left(f_{a} \sigma_{T_{a}}^{2}\right)$, (c) midlatitude $\left(f_{m} \sigma_{T_{m}}^{2}\right)$, and (d) rest-of-theglobe $\left(f_{r} \sigma_{T_{r}}^{2}\right)$ variance components in the CESM-LE. Preindustrial estimates are shown by the horizontal red dashed lines in each panel. The noisy time series are the ensemble estimates of the variance and covariance components [see Eqs. (7) and (8)]. Forced estimates derived from smoothing the noisy ensemble time series are shown by the black dashed lines. Ninety-five percent bootstrap confidence intervals for the preindustrial and forced estimates are shown by horizontal red and black solid lines, respectively. The terms $f_{a}, f_{m}$, and $f_{r}$ represent the fractions of global area occupied by the Arctic, midlatitudes, and the rest of the globe. Note the different scales on the $y$ axes.

transition from historical to RCP8.5 forcing in the early twenty-first century, the contribution of the covariance increases at a nearly constant rate until the end of the integration by $5 \%$, while the contribution of the ocean variance decreases by $\sim 10 \%$, with the decrease being more rapid after 2020. Compensating for this more rapid decrease, the contribution of the land variance rises after 2020.

In Fig. 4, we show the 95\% data ellipse of land and ocean temperatures constructed from the 30-yr smoothed estimates of the forced variances and covariance at 1935 (Fig. 4, blue) and at 2085 (Fig. 4, red). The changes in the ellipse reveal two important characteristics of the forced variability response that are both interesting and not obvious from the decomposition in Fig. 2. First, the ellipse in the twenty-first century is stretched along the major axis and is more tilted toward the land axis ( $x$ axis in Fig. 4) than in the early twentieth century [see Eqs. (16)-(18)]. These changes in the shape and orientation of the ellipse indicate that land and ocean temperatures become more correlated (see Fig. 1 and section 2c), that is, they vary more coherently in a warmer climate. Second, the ellipse encloses a wider range of land temperatures in a warmer climate. That is, there is a greater probability of extreme fluctuations in land temperature relative to the late twentyfirst-century mean state.
In summary, the framework reveals 1) a large contribution ( $>20 \%$ ) of the land and ocean temperature covariance to global annual temperature variance, 2) greater twenty-first-century global and land temperature variance that are significantly different from their preindustrial estimates, 3 ) ocean temperature variance that is not significantly different from its preindustrial estimate throughout the twentieth and twenty-first centuries, and 4) greater twenty-first-century covariance and correlation between land and ocean temperature with an increased risk of extreme fluctuations in land temperature.

\section{b. Forced interannual variability of monthly mean temperature: Arctic/midlatitude/rest-of-the-globe decomposition}

The loss of Arctic sea ice under increased greenhouse gas forcing is one of the largest and most visible manifestations of climate change (IPCC 2013). Arctic sea ice extent loss has a pronounced impact not only on mean surface warming but also on temperature variability (Screen and Simmonds 2010; Serreze and Barry 2011). In the CESM-LE, as in other climate models, Arctic sea ice extent loss is particularly large at the end of the summer melt season in September (Jahn et al. 2016). For these reasons, we begin our assessment of the forced 


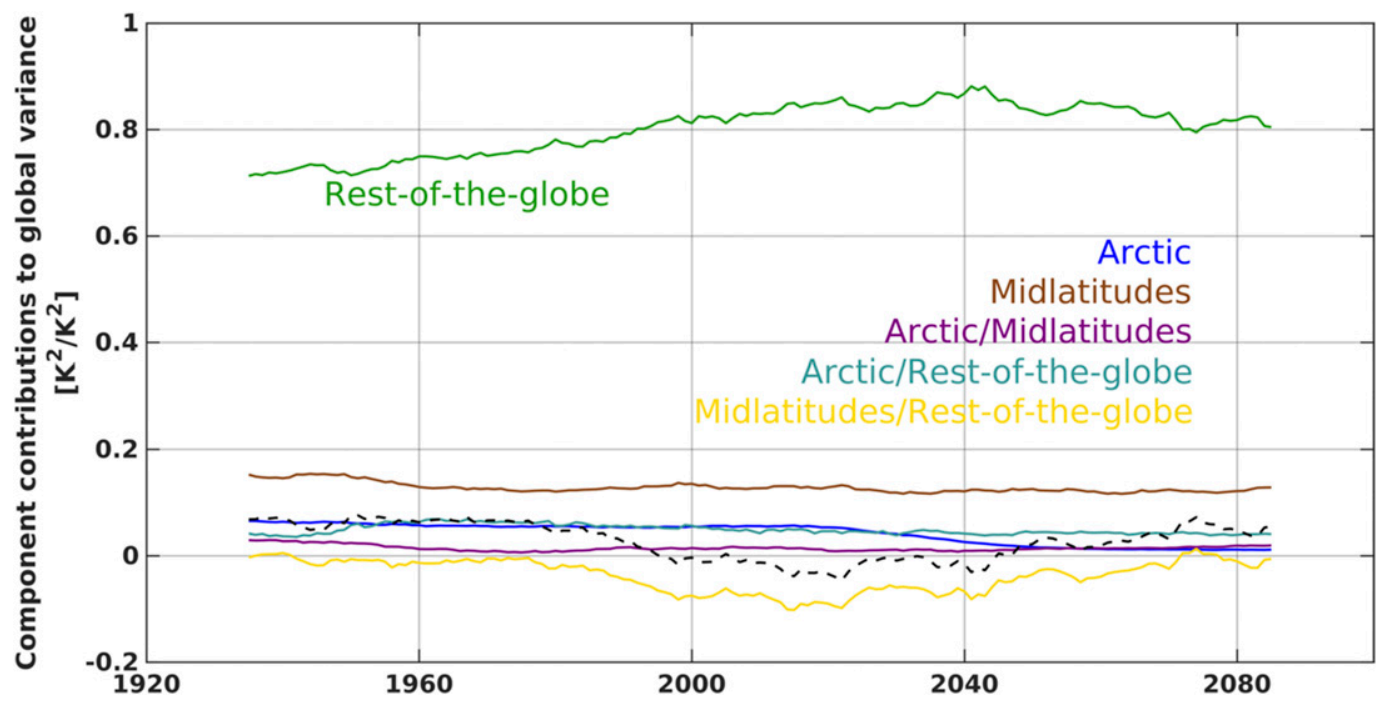

FIG. 6. Contributions of Arctic (blue), midlatitude (brown), and rest-of-the-globe (green) variance components, and Arctic/midlatitude (purple), Arctic/rest-of-the-globe (cyan), and midlatitude/rest-of-the-globe (yellow) covariance components to global September temp variance. The contributions are computed as ratios of the components and teleconnections relative to global September temp variance. The sum of the covariance contributions is shown by the black dashed line.

interannual monthly temperature variability with a focus on the month of September. Specifically, we decompose the interannual variance in global September temperature into variance and covariance components associated with the Arctic $\left(70^{\circ}-90^{\circ} \mathrm{N}\right)$, the northern midlatitudes $\left(30^{\circ}-70^{\circ} \mathrm{N}\right)$, and the rest-of-the-globe regions in the CESM-LE.

Figure 5 shows the forced evolution of the variance components arising from the September decomposition. The Arctic variance (Fig. 5b) stays relatively constant from the start of the integration until 2020, after which it decreases in a striking nonlinear fashion, coinciding with the loss of September sea ice in the CESM-LE (not shown). As most of the September sea ice is lost by 2060, the Arctic variance reduces asymptotically to a level that is smaller than its early twentieth-century level by a remarkable $75 \%$. In contrast with the strongly decreasing Arctic variance, the midlatitude variance (Fig. 5c) remains largely constant throughout the integration with a small increase toward the end of the integration. The rest-of-the-globe variance (Fig. 5d), on the other hand, grows steadily until the end of the integration, emerging from its preindustrial state in the mid-twentieth century. Interestingly, the changes in the smoothed covariance estimates associated with this three-region system were found to be negligible and therefore are not shown.

We next assess the contributions of the regional variances and covariances to global September variance in Fig. 6 as ratios compared to global September variance. We find that the rest-of-the-globe variance has the greatest contribution to global September variance throughout the integration $(>90 \%)$. The Arctic and midlatitude variances have much smaller contributions, which is not surprising considering the smaller fractions of global area occupied by the Arctic (3\%) and the midlatitudes $(22 \%)$ compared to the rest of the globe $(75 \%)$. Unlike the land/ocean system where the covariance has a large and positive contribution (section 3a), the covariances here have a small and negative total contribution.

How does the large September Arctic sea ice extent loss affect the temperature probabilities in the Arctic/ midlatitude/rest-of-the-globe system? We address this question using data ellipses. Assuming the pairwise distributions of the Arctic, midlatitude, and rest-of-theglobe temperatures to be Gaussian, we visualize the changes in probabilities using $95 \%$ data ellipses (Fig. 7). We find that the large decrease in the Arctic variance results in a large shrinkage of the Arctic/midlatitude [Fig. 7a; see Eqs. (16)-(18)] and the Arctic/rest-of-theglobe (Fig. 7b) September temperature ellipses along their major axes. Simply put, the ellipses show the probability of extreme fluctuations of September Arctic temperature about the twenty-first-century mean state is greatly reduced.

Fascinated by the large reduction in the September Arctic variance, we next ask: How do the variances and covariances associated with the other months respond to historical and RCP8.5 forcing? Is there a seasonal character to the response? Are the covariance changes 

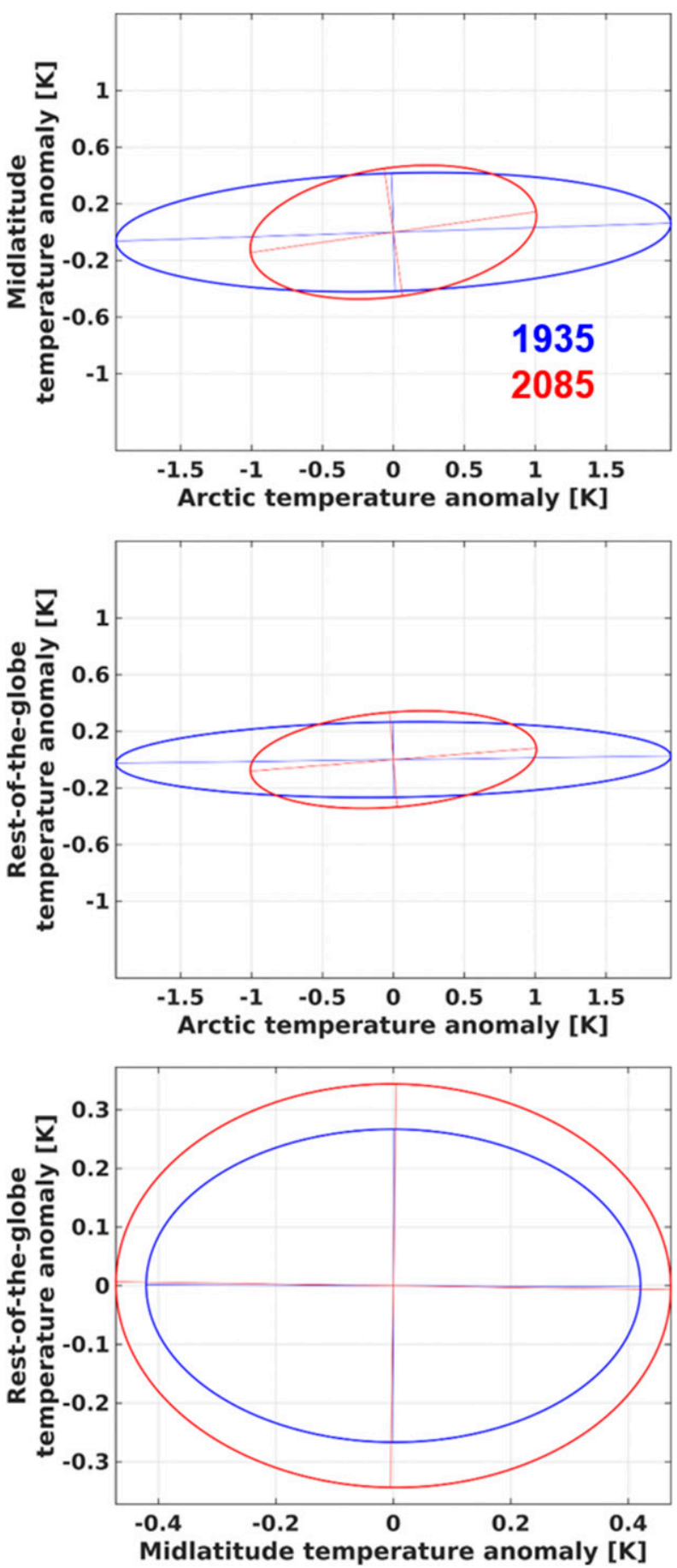

FIG. 7. Ninety-five percent data ellipses for September (a) Arctic and midlatitude, (b) Arctic and rest-of-the-globe, and (c) midlatitude and rest-of-the-globe temp anomalies at 1935 (blue) and 2085 (red). The ellipses were constructed from forced estimates of the variances and covariances associated with the Arctic/midlatitude/rest-of-the-globe system in the CESM-LE. Anomalies are calc as devs from the ensemble mean. negligible in all months, or just in September? To address these questions, we perform a month-bymonth decomposition of interannual variance in global monthly temperature into variance and covariance components arising from the Arctic/midlatitude/restof-the-globe system. The forced variances varied by more than an order of magnitude from month to month. Therefore, for ease of comparing across different months, we normalize by taking the ratios of the forced variances to their unforced estimates. We present the ratios in Fig. 8. We find that the forced response of the Arctic variance (Fig. 8b) has a strong seasonal character: it displays large decreases in the fall, minor decreases in the spring, and negligible decreases in the summer and winter. The forced response of the midlatitude variance (Fig. 8c) is weak, except in October and November, during which it displays significant decreases, and in July, during which it displays a striking increase $(\sim 120 \%)$. The forced response of the rest-ofthe-globe variance (Fig. 8d) is more uniform: it increases in most months. As in September, the changes in the covariances in all months were found to be negligible and therefore are not presented.

Intrigued by the large increase in the July midlatitude variance, we more fully explore in Fig. 9 the variance components arising from the decomposition of global July variance. We find that the Arctic variance (Fig. 9b) remains constant until 1980, after which, coinciding with the commencement of July sea ice loss in the CESM-LE (not shown), it decreases until 2040. After 2040, despite continued sea ice loss in the CESM-LE and coinciding with the increase in the midlatitude variance (Fig. 9c), the Arctic variance remarkably grows back to its preindustrial value.

The contributions of the regional variances and covariances to global July variance are assessed in Fig. 10 as ratios. We find that the rest-of-the-globe variance has the greatest contribution $(>80 \%)$ to global July variance (Fig. 10) as in Fig. 6. Further as in Fig. 6, we find that the contributions of the Arctic and midlatitude variances, and the covariances, are much smaller than the contributions of the rest-of-the-globe variance to global July temperature variance.

Finally, we assess changes in the temperature probability distributions induced by the substantial increases in the July midlatitude variance. Again, assuming the pairwise distributions of the Arctic, midlatitude, and rest-of-the-globe temperatures to be Gaussian, we visualize the changes in probabilities using $95 \%$ data ellipses (Fig. 11). We find that the increase in the midlatitude variance results in only a marginal stretch of the midlatitude/rest-of-the-globe [Fig. 11c; see Eqs. (16)-(18)] July temperature ellipse along its major axes. 
a. Global forced to preindustrial variance ratio

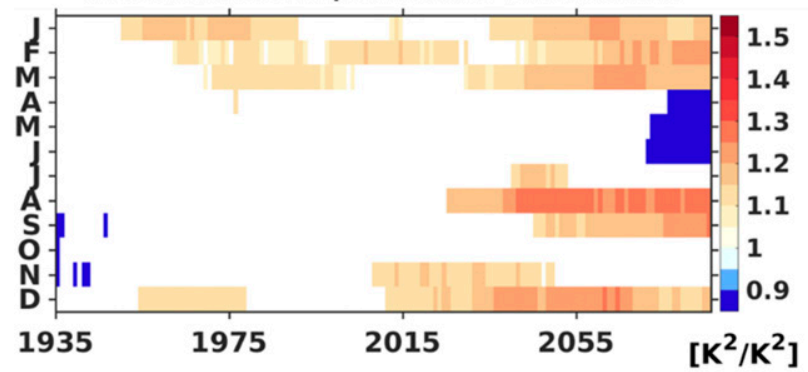

b. Arctic forced to preindustrial variance ratio

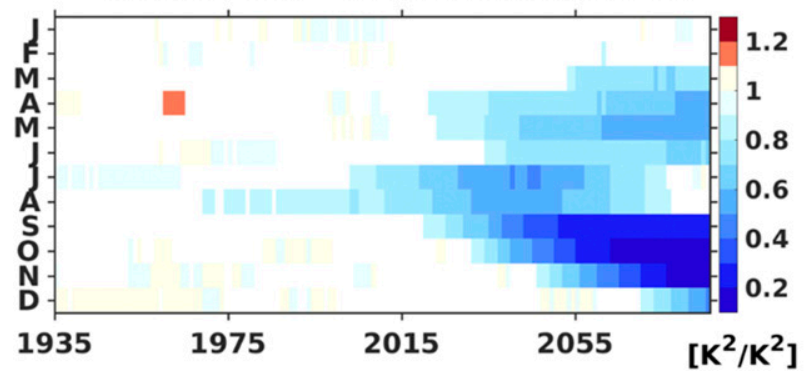

c. Midlatitude forced to preindustrial variance ratio

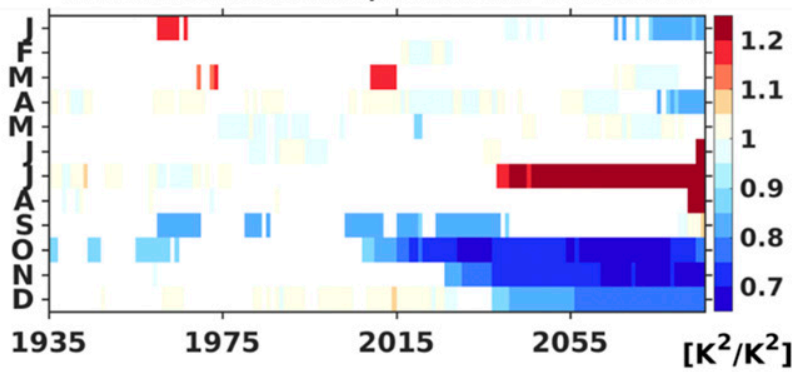

d. Rest-of-the-globe forced to preindustrial variance ratio

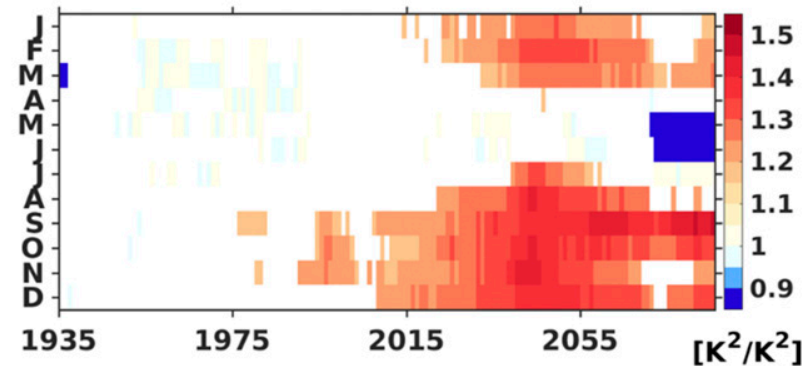

FIG. 8. Ratios of (a) interannual global monthly temp variance, (b) Arctic variance component, (c) midlatitude variance component, and (d) rest-of-the-globe variance components estimated in the CESM-LE to their preindustrial estimates. Ratios where the forced estimates do not differ significantly from their preindustrial estimates are shown in white. Note the different color scales.

We further find that the changes in the geometrical properties of the Arctic/midlatitude (Fig. 11a) and the Arctic/rest-of-the-globe ellipse (Fig. 11b) are negligible. That is, the probabilities of the fluctuations about the Arctic, midlatitude, and rest-of-the-globe July temperatures remain more or less unchanged in a warmer climate.

In summary, our investigations of the forced interannual monthly temperature variability associated with the Arctic/midlatitude/rest-of-the-globe system
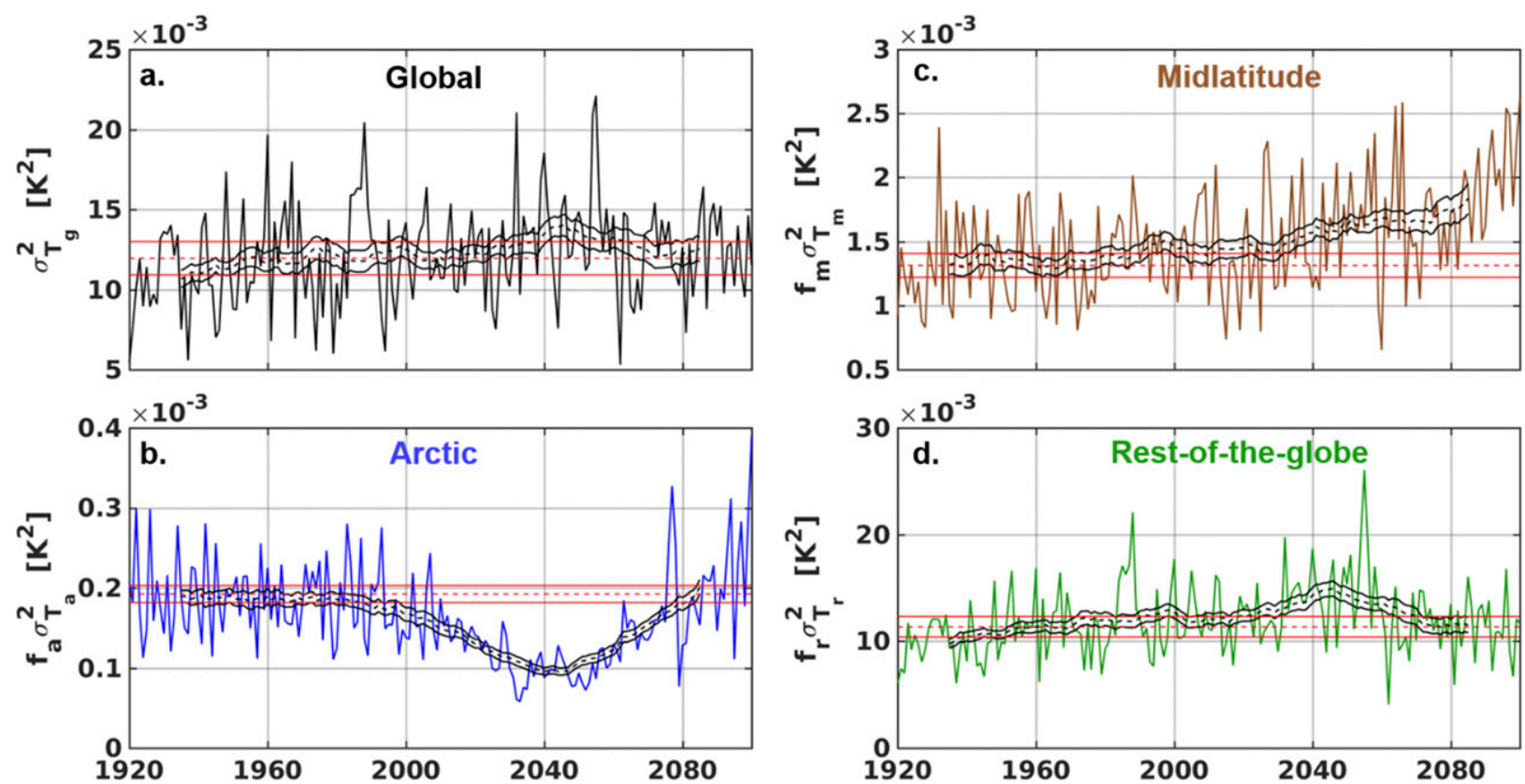

FIG. 9. As in Fig. 5, but for July. 


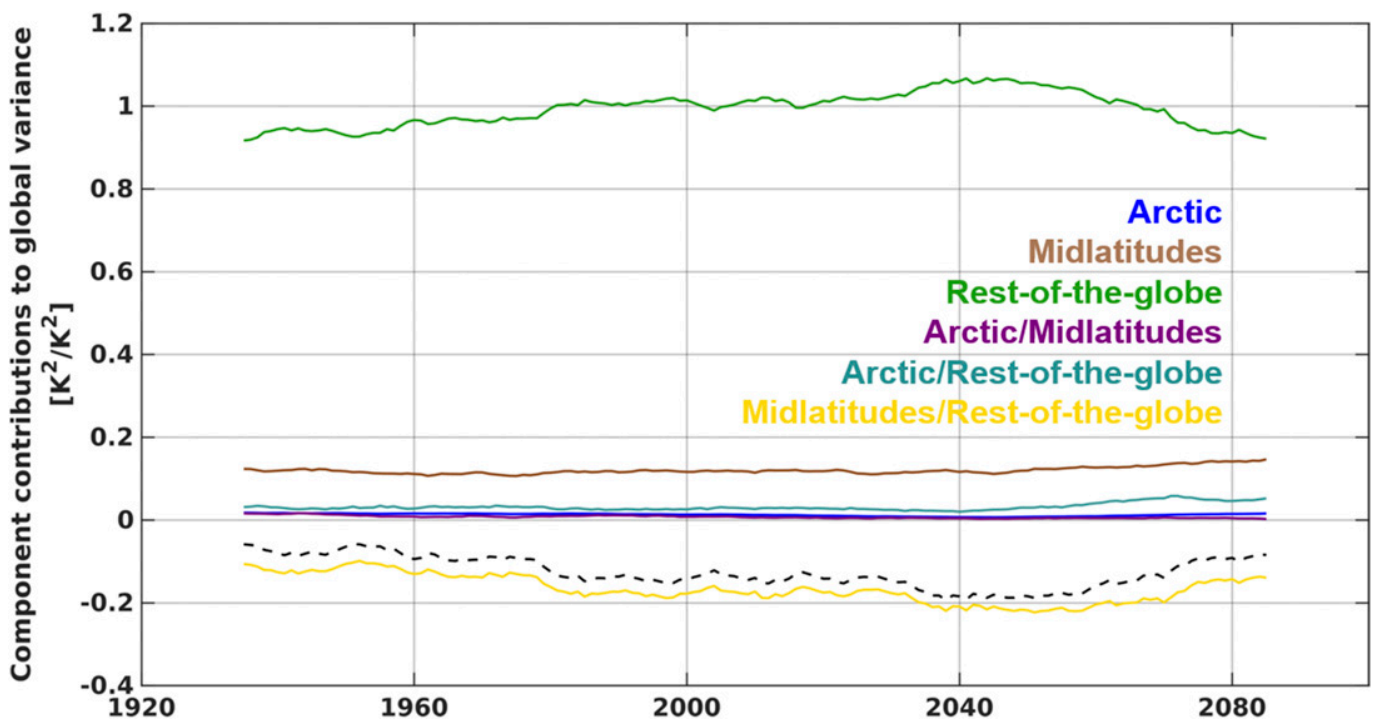

FIG. 10. As in Fig. 6, but for July.

revealed 1) large twenty-first-century Arctic temperature variance decreases in the fall months, 2) large twenty-first-century midlatitude temperature variance increases in the summer months, 3) negligible changes in temperature covariances in most months, and 4) large twenty-first-century increases in the rest-of-the-globe temperature variance in most months.

\section{Summary and discussion}

Broadening the scope of variability studies, we have here developed a simple framework that facilitates a unified assessment of the interannual variances and covariances associated with a system of interacting regions in climate model ensembles. The three central constituents of the framework are 1) a decomposition of global variability into regional variance and covariance components, 2) the computation of the evolving components in an ensemble of climate model simulations under transient forcing, and 3) the application of a statistical resampling method to quantify the time of emergence of forced variability signals. As our investigations have demonstrated, the three constituents combine to provide a simple yet comprehensive assessment of the forced response of regional interannual variability.

Our investigations have revealed interannual variability changes in the CESM-LE that are consistent with results from literature. For example, we found large decreases in fall Arctic temperature variance (Fig. 8b). These decreases occurring because of the loss of sea ice cover and the moderating influence of the exposed waters are a consistent feature across a host of variability studies (e.g., Räisänen 2001; Stouffer and Wetherald 2007; Boer 2009; LaJoie and DelSole 2016). The increases in the summer midlatitude temperature variance (Fig. 8c) are also a robust result of variability studies and have been linked to a drying of continental land because of depletion of soil moisture (e.g., Räisänen 2001; Stouffer and Wetherald 2007; Scherrer et al. 2008; Fischer et al. 2012).

While our investigations have uncovered variability changes that are robust across existing twenty-firstcentury model simulations, have a known physical basis, and perhaps, therefore, are not surprising, there are three important findings that are shown here for the first time. First, the land temperature variance (Fig. 2b) increases to almost 1.5 times its preindustrial level. This increase will manifest as an enhanced likelihood of extreme land temperatures (see Fig. 4). These extreme heat events will be superimposed upon a mean state that is almost $5^{\circ} \mathrm{C}$ warmer than the present day in the CESM-LE (analysis not shown) and will have important implications for the society and ecology (e.g., Ciais et al. 2005; Larsen 2006; Liu et al. 2010). We also find that the land and ocean temperature covariance increases in a warmer climate, suggesting that land and ocean temperatures will vary more coherently in a warmer climate and as a result the knowledge of sea surface temperatures (SSTs) may contribute to increased predictability of land temperatures (e.g., Årthun et al. 2017). Third, we find that July temperature variance in the Arctic grows toward the end of the twenty-first century. While the physical mechanisms underlying this growth are unknown to us at present, the fact that the growth occurs 

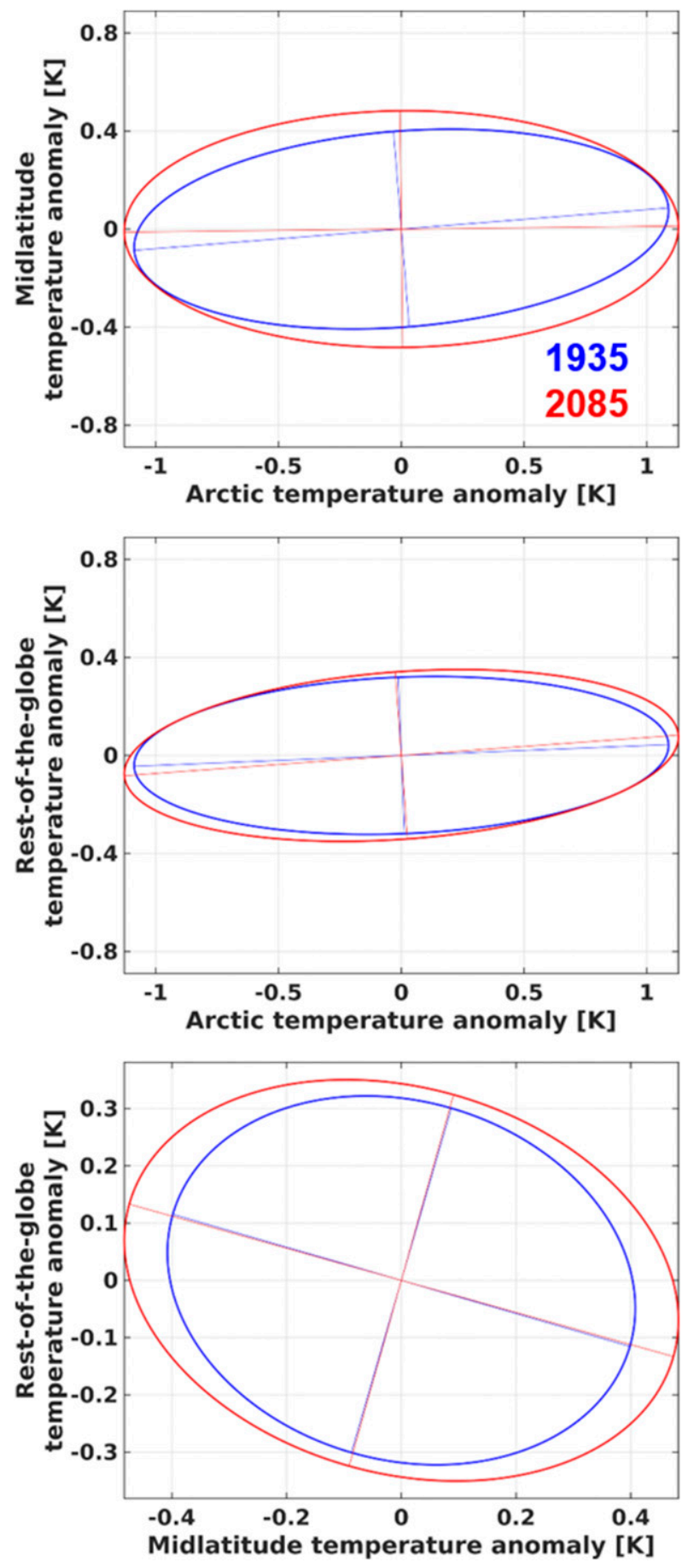

FIG. 11. As in Fig. 7, but for July.

despite continued sea ice loss in the CESM-LE suggests the influence of processes nonlocal to the Arctic and warrants further investigation. Finally, the land temperature variance (Fig. 2b) and the September Arctic (Fig. 5b) and midlatitude (Fig. 5c) temperature variances emerge from their preindustrial states in the first few decades of the twentieth century. If the CESM-LE accurately captures the variability of these regions, an assumption we have not tested, the signals of forced historical variability would be expected to be embedded in the observed record. These results therefore motivate future studies to perform a formal detection and attribution analysis leveraging observations and climate model simulations to identify these signals in observations and attribute them to external forcings (e.g., Hegerl and Zwiers 2011).

An important and perhaps fundamental insight that has emerged from our investigations is the importance of regional covariances to global variance on interannual time scales as demonstrated by the major contribution of the land and ocean temperature covariance to global variance (Fig. 3). Our finding that regional covariances can have an enormous influence on global interannual variance suggests that studies seeking to understand the relationship between global variance and regional variability (e.g., Sutton et al. 2015) may benefit by taking into account regional covariances.

The investigations in this paper are limited to the variability associated with systems consisting of two and three regions in a single climate model ensemble. The applications of the framework, however, are more general. The framework, through the decomposition that can admit an arbitrary number of regions, can be adapted to the assessment of the variance and covariance components arising from as many number of regions as desired on the globe. This flexibility can enable an integrated study of the modes of climate variability that often couple numerous regions on the planet. For example, the ENSO phenomenon, a prominent mode of interannual variability, is concentrated in the tropical Pacific but has teleconnections to remote regions of the globe and therefore is of great interest for climate projections (Collins et al. 2010). How will the year-to-year ENSO variability change in a warmer climate? How will the numerous ENSO teleconnections change under mean warming? When will these changes emerge? These are the kinds of questions that can be addressed with the framework in a comprehensive manner.

Finally, we list two opportunities for future research. Given the potentially broad implications of our findings, future work could assess their robustness across existing model ensembles, for example, those from phase 5 of the Coupled Model Intercomparison Project (CMIP5). The ensemble framework presented in this paper provides a natural means for this purpose. In this context, the production of large ensemble simulations by individual modeling groups participating in the ongoing CMIP6 experiments (Eyring et al. 2016) will be 
particularly useful. Another obvious next step would be to extend the framework to the assessment of covariances between variables. The methods in this paper are limited to the covariance of one variable between different regions. It would be straightforward and useful to extend these methods to quantify the forced evolution and time of emergence of covariance between variables, for example, the covariance between tropical Pacific SSTs and rainfall patterns in various ENSO-affected regions around the world (e.g., Perry et al. 2017).

Acknowledgments. The authors thank Andrew Poppick and Timothy DelSole for useful discussions related to this work, the Yellowstone CESM CSL for computing resources, and the scientists and software engineers who build CESM. The authors also acknowledge comments by two anonymous reviewers that helped improve the quality of the paper. This work was funded by start-up funds awarded to J. E. Kay by the University of Colorado. J. B. W. was partially supported by NSF-OCE1245944. A. G. P. was supported by the Regional and Global Climate Modeling Program of the U.S. Department of Energy's Office of Science, Cooperative Agreement DE-FC02-97ER62402. NCAR is sponsored by the National Science Foundation.

\section{REFERENCES}

Addo-Bediako, A., S. L. Chown, and K. J. Gaston, 2000: Thermal tolerance, climatic variability and latitude. Proc. Roy Soc. London, 267B, 739-745, https://doi.org/10.1098/ rspb.2000.1065.

Årthun, M., T. Eldevik, E. Viste, H. Drange, T. Furevik, H. L. Johnson, and N. S. Keenlyside, 2017: Skillful prediction of northern climate provided by the ocean. Nat. Commun., 8, 16152, https://doi.org/10.1038/ncomms16152.

Bindoff, N. L., and Coauthors, 2013: Detection and attribution of climate change: From global to regional. Climate Change 2013: The Physical Science Basis, T. F. Stocker et al., Eds., Cambridge University Press, 867-952, https://doi.org/10.1017/ CBO9781107415324.022.

Bjerknes, J., 1969: Atmospheric teleconnections from the equatorial Pacific. Mon. Wea. Rev., 97, 163-172, https://doi.org/ 10.1175/1520-0493(1969)097<0163:ATFTEP > 2.3.CO;2.

Boer, G. J., 2009: Changes in interannual variability and decadal potential predictability under global warming. J. Climate, 22 3098-3109, https://doi.org/10.1175/2008JCLI2835.1.

Ciais, P., and Coauthors, 2005: Europe-wide reduction in primary productivity caused by the heat and drought in 2003. Nature, 437, 529-533, https://doi.org/10.1038/nature03972.

Collins, M., and M. R. Allen, 2002: Assessing the relative roles of initial and boundary conditions in interannual to decadal climate predictability. J. Climate, 15, 3104-3109, https://doi.org/ 10.1175/1520-0442(2002)015<3104:ATRROI>2.0.CO;2.

— and Coauthors, 2010: The impact of global warming on the tropical Pacific Ocean and El Niño. Nat. Geosci., 3, 391-397, https://doi.org/10.1038/ngeo868.
Deser, C., A. Phillips, V. Bourdette, and H. Teng, 2012: Uncertainty in climate change projections: The role of internal variability. Climate Dyn., 38, 527-546, https://doi.org/10.1007/ s00382-010-0977-x.

Efron, B., 1981: Nonparametric estimates of standard error: The jackknife, the bootstrap and other methods. Biometrika, 68, 589-599, https://doi.org/10.1093/biomet/ 68.3.589.

Eyring, V., S. Bony, G. A. Meehl, C. A. Senior, B. Stevens, R. J. Stouffer, and K. E. Taylor, 2016: Overview of the Coupled Model Intercomparison Project phase 6 (CMIP6) experimental design and organization. Geosci. Model Dev., 9, 1937-1958, https://doi.org/10.5194/gmd-9-1937-2016.

Fischer, E. M., S. I. Seneviratne, P. L. Vidale, D. Lüthi, and C. Schär, 2007: Soil moisture-atmosphere interactions during the 2003 European summer heat wave. J. Climate, 20, 50815099, https://doi.org/10.1175/JCLI4288.1.

_ J. Rajczak, and C. Schär, 2012: Changes in European summer temperature variability revisited. Geophys. Res. Lett., 39, L19702, https://doi.org/10.1029/2012GL052730.

Friendly, M., G. Monette, and J. Fox, 2013: Elliptical insights: Understanding statistical methods through elliptical geometry. Stat. Sci., 28, 1-39, https://doi.org/10.1214/ 12-STS402.

Giorgi, F., and X. Bi, 2009: Time of emergence (TOE) of GHGforced precipitation change hot-spots. Geophys. Res. Lett., 36, L06709, https://doi.org/10.1029/2009GL037593.

Hannachi, A., I. T. Jolliffe, and D. B. Stephenson, 2007: Empirical orthogonal functions and related techniques in atmospheric science: A review. Int. J. Climatol., 27, 1119-1152, https://doi.org/ 10.1002/joc.1499.

Hawkins, E., and R. Sutton, 2012: Time of emergence of climate signals. Geophys. Res. Lett., 39, L01702, https://doi.org/ 10.1029/2011GL050087.

, and Coauthors, 2014: Uncertainties in the timing of unprecedented climates. Nature, 511, E3-E5, https://doi.org/ 10.1038/nature13523.

Hegerl, G., and F. Zwiers, 2011: Use of models in detection and attribution of climate change. Wiley Interdiscip. Rev.: Climate Change, 2, 570-591, https://doi.org/10.1002/wcc.121.

Henze, N., and B. Zirkler, 1990: A class of invariant consistent tests for multivariate normality. Commun. Stat. Theory Methods, 19, 3595-3617, https://doi.org/10.1080/ 03610929008830400.

Holmes, C. R., T. Woollings, E. Hawkins, and H. de Vries, 2016: Robust future changes in temperature variability under greenhouse gas forcing and the relationship with thermal advection. J. Climate, 29, 2221-2236, https://doi.org/10.1175/ JCLI-D-14-00735.1.

Huntingford, C., P. D. Jones, V. N. Livina, T. M. Lenton, and P. M. Cox, 2013: No increase in global temperature variability despite changing regional patterns. Nature, 500, 327-330, https://doi.org/10.1038/nature12310.

Hurrell, J. W., and Coauthors, 2013: The Community Earth System Model: A framework for collaborative research. Bull. Amer. Meteor. Soc., 94, 1339-1360, https://doi.org/10.1175/BAMS-D12-00121.1.

IPCC, 1990: Climate Change: The IPCC Scientific Assessment. Cambridge University Press, 414 pp., https://www.ipcc.ch/ ipccreports/far/wg_I/ipcc_far_wg_I_full_report.pdf.

2013: Climate Change 2013: The Physical Science Basis. Cambridge University Press, 1535 pp., https://doi.org/10.1017/ CBO9781107415324. 
Jahn, A., J. E. Kay, M. M. Holland, and D. M. Hall, 2016: How predictable is the timing of a summer ice-free Arctic? Geophys. Res. Lett., 43, 9113-9120, https://doi.org/10.1002/ 2016 GL070067.

Jolliffe, I. T., 2002: Principal Component Analysis. 2nd ed. Springer, $487 \mathrm{pp}$.

Katz, R. W., and B. G. Brown, 1992: Extreme events in a changing climate: Variability is more important than averages. Climatic Change, 21, 289-302, https://doi.org/10.1007/ BF00139728.

Kay, J. E., and Coauthors, 2015: The Community Earth System Model (CESM) large ensemble project: A community resource for studying climate change in the presence of internal climate variability. Bull. Amer. Meteor. Soc., 96, 1333-1349, https://doi.org/10.1175/BAMS-D-13-00255.1.

Kunkel, K. E., R. A. Pielke Jr., and S. A. Changnon, 1999: Temporal fluctuations in weather and climate extremes that cause economic and human health impacts: A review. Bull. Amer. Meteor. Soc., 80, 1077-1098, https://doi.org/10.1175/1520-0477 (1999) $080<1077:$ TFIWAC $>2.0$. CO;2.

LaJoie, E., and T. DelSole, 2016: Changes in internal variability due to anthropogenic forcing: A new field significance test. J. Climate, 29, 5547-5560, https://doi.org/10.1175/ JCLI-D-15-0718.1.

Lamarque, J.-F., and Coauthors, 2010: Historical (1850-2000) gridded anthropogenic and biomass burning emissions of reactive gases and aerosols: Methodology and application. Atmos. Chem. Phys., 10, 7017-7039, https://doi.org/10.5194/ acp-10-7017-2010.

Larsen, J., 2006: Setting the record straight: More than 52,000 Europeans died from heat in summer 2003. Earth Policy Institute, accessed 20 August 2017, http://www.earthpolicy.org/plan_b_updates/2006/update56.

Leeds, W. B., E. J. Moyer, and M. L. Stein, 2015: Simulation of future climate under changing temporal covariance structures. Adv. Stat. Climatol. Meteor. Oceanogr., 1,1-14, https://doi.org/ 10.5194/ascmo-1-1-2015.

Leith, C. E., 1978: Predictability of climate. Nature, 276, 352-355, https://doi.org/10.1038/276352a0.

Liu, Y., J. Stanturf, and S. Goodrick, 2010: Trends in global wildfire potential in a changing climate. For. Ecol. Manage., 259, 685697, https://doi.org/10.1016/j.foreco.2009.09.002.

Lorenz, E. N., 1963: Deterministic nonperiodic flow. J. Atmos. Sci., 20, 130-141, https://doi.org/10.1175/1520-0469(1963)020<0130: $\mathrm{DNF}>2.0 . \mathrm{CO} ; 2$.

Meehl, G. A., and C. Tebaldi, 2004: More intense, more frequent, and longer lasting heat waves in the 21 st century. Science, $\mathbf{3 0 5}$, 994-997, https://doi.org/10.1126/science.1098704.

Meinshausen, M., and Coauthors, 2011: The RCP greenhouse gas concentrations and their extensions from 1765 to 2300. Climatic Change, 109, 213-241, https://doi.org/10.1007/ s10584-011-0156-z.

Mora, C., and Coauthors, 2013: The projected timing of climate departure from recent variability. Nature, 502, 183-187, https://doi.org/10.1038/nature12540.

Perry, S. J., S. McGregor, A. Sen Gupta, and M. H. England, 2017: Future changes to El Niño-Southern Oscillation temperature and precipitation teleconnections. Geophys. Res. Lett., 44, 10 608-10 616, https://doi.org/10.1002/2017GL074509.

Politis, D. N., J. P. Romano, and M. Wolf, 1999: Subsampling. Springer, $347 \mathrm{pp}$.

Poppick, A., D. J. McInerney, E. J. Moyer, and M. L. Stein, 2016: Temperatures in transient climates: Improved methods for simulations with evolving temporal covariances. Ann. Appl. Stat., 10, 477-505, https://doi.org/10.1214/16-AOAS903.

Porter, J. R., and M. A. Semenov, 2005: Crop responses to climatic variation. Philos. Trans. Roy. Soc. London, 360B, 2021-2035, https://doi.org/10.1098/rstb.2005.1752.

Räisänen, J., 2001: $\mathrm{CO}_{2}$-induced climate change in CMIP2 experiments: Quantification of agreement and role of internal variability. J. Climate, 14, 2088-2104, https://doi.org/10.1175/ 1520-0442(2001)014<2088:CICCIC >2.0.CO;2.

Rajagopalan, B., and U. Lall, 1998: Interannual variability in western US precipitation. J. Hydrol., 210, 51-67, https://doi.org/ 10.1016/S0022-1694(98)00184-X.

Robine, J.-M., S. L. K. Cheung, S. Le Roy, H. Van Oyen, C. Griffiths, J.-P. Michel, and F. R. Herrmann, 2008: Death toll exceeded 70,000 in Europe during the summer of 2003. C. R. Biol., 331, 171-178, https://doi.org/10.1016/ j.crvi.2007.12.001

Schär, C., P. L. Vidale, D. Lüthi, C. Frei, C. Häberli, M. A. Liniger, and C. Appenzeller, 2004: The role of increasing temperature variability in European summer heatwaves. Nature, 427, 332336, https://doi.org/10.1038/nature02300.

Scherrer, S. C., M. A. Liniger, and C. Appenzeller, 2008: Distribution changes of seasonal mean temperature in observations and climate change scenarios. Climate Variability and Extremes during the Past 100 Years, S. Brönnimann et al., Eds. Advances in Global Change Research, Vol. 33, Springer, 251-267, http://doi.org/10.1007/978-1-4020-6766-2_17.

Schneider, T., and S. M. Griffies, 1999: A conceptual framework for predictability studies. J. Climate, 12, 3133-3155, https:// doi.org/10.1175/1520-0442(1999)012<3133:ACFFPS >2.0.CO;2.

Screen, J. A., and I. Simmonds, 2010: Increasing fall-winter energy loss from the Arctic Ocean and its role in Arctic temperature amplification. Geophys. Res. Lett., 37, L16707, https://doi.org/ 10.1029/2010GL044136.

Serreze, M. C., and R. G. Barry, 2011: Processes and impacts of Arctic amplification: A research synthesis. Global Planet. Change, 77, 85-96, https://doi.org/10.1016/j.gloplacha.2011.03.004.

Simmons, A. J., J. M. Wallace, and G. W. Branstator, 1983: Barotropic wave propagation and instability, and atmospheric teleconnection patterns. J. Atmos. Sci., 40, 1363-1392, https://doi.org/ 10.1175/1520-0469(1983)040<1363:BWPAIA > 2.0.CO;2.

Stouffer, R. J., and R. T. Wetherald, 2007: Changes of variability in response to increasing greenhouse gases. Part I: Temperature. J. Climate, 20, 5455-5467, https://doi.org/10.1175/ 2007JCLI1384.1.

Sutton, R., E. Suckling, and E. Hawkins, 2015: What does global mean temperature tell us about local climate? Philos. Trans. Roy. Soc. London, 373A, 20140426, https://doi.org/10.1098/ rsta.2014.0426.

Thompson, D. W. J., and J. M. Wallace, 1998: The Arctic Oscillation signature in the wintertime geopotential height and temperature fields. Geophys. Res. Lett., 25, 1297-1300, https:// doi.org/10.1029/98GL00950.

— E. A. Barnes, C. Deser, W. E. Foust, and A. S. Phillips, 2015: Quantifying the role of internal climate variability in future climate trends. J. Climate, 28, 6443-6456, https://doi.org/ 10.1175/JCLI-D-14-00830.1.

Toth, Z., 1991: Circulation patterns in phase space: A multinormal distribution? Mon. Wea. Rev., 119, 1501-1511, https://doi.org/ 10.1175/1520-0493(1991)119<1501:CPIPSA > 2.0.CO;2.

Trenberth, K. E., and D. J. Shea, 1987: On the evolution of the Southern Oscillation. Mon. Wea. Rev., 115, 3078-3096, https:// doi.org/10.1175/1520-0493(1987)115<3078:OTEOTS>2.0.CO;2. 
Wallace, J. M., and D. S. Gutzler, 1981: Teleconnections in the geopotential height field during the Northern Hemisphere winter. Mon. Wea. Rev., 109, 784-812, https://doi.org/10.1175/ 1520-0493(1981)109<0784:TITGHF>2.0.CO;2.

Wetherald, R. T., 2009: Changes of variability in response to increasing greenhouse gases. Part II: Hydrology. J. Climate, 22, 6089-6103, https://doi.org/10.1175/2009JCLI2834.1.

Wheeler, T. R., P. Q. Craufurd, R. H. Ellis, J. R. Porter, and P. V. Vara Prasad, 2000: Temperature variability and the yield of annual crops. Agric. Ecosyst. Environ., 82, 159-167, https://doi.org/10.1016/S0167-8809(00)00224-3.

Wilks, D. S., 2011: Statistical Methods in the Atmospheric Sciences. International Geophysics Series, Vol. 100, Academic Press, 676 pp. Yettella, V., and J. E. Kay, 2017: How will precipitation change in extratropical cyclones as the planet warms? Insights from a large initial condition climate model ensemble. Climate Dyn., 49, 1765-1781, https://doi.org/10.1007/ s00382-016-3410-2. 